\title{
Uma nova combinação em Deltocephalinae (Hemiptera, Cicadellidae) ${ }^{1}$
}

\author{
Keti Maria Rocha Zanol ${ }^{2}$ \\ 1 Contribuição número 1465 do Departamento de Zoologia, Universidade Federal do Paraná. \\ ${ }^{2}$ Departamento de Zoologia, Universidade Federal do Paraná. Caixa Postal 19020, 81531-980 Curitiba, Paraná, Brasil. \\ Bolsista do CNPq.
}

\author{
ABSTRACT. A new combination in Deltocephalinae (Hemiptera, Cicadellidae). Sinchonoa particula (DeLong, \\ 1982) comb. nov. the species is redescribed and illustrated. \\ KEY WORDS. Redescription, Sinchonoa, taxonomy.
}

RESUMO. Sinchonoa particula (DeLong, 1982) comb. nov. redescrição e ilustração da espécie são dadas. PALAVRAS CHAVES. Redescrição, Sinchonoa, taxonomia.

\section{Sinchonoa particula (DeLong,1982) comb. nov.} Figs 1-8

Frequenamia particula DeLong, 1982: 188. Localidade-tipo: Panamá, Chiriqui.

Cabeça levemente mais larga que o pronoto. Coroa de cor marfim com a margem anterior rugosa. Região frontal levemente intumescida, rugosa e margeada de marrom. Região discal e face dourada. Ocelos na margem anterior, não visíveis de cima. Sutura coronal ultrapassando a metade do comprimento da coroa. Sutura frontoclipeal estendendo-se além dos ocelos. Anteclípeo mais largo no ápice. Genas com reentrância abaixo dos olhos.

Pronoto dourado com manchas marrons e pequenas áreas amareladas. Asas anteriores douradas com áreas arredondadas brancas das quais cinco no clavo; margem costal com áreas triangulares marrons. Duas células anteapicais fechadas. Clavo com uma veia extranumerária entre $1 \mathrm{~A}$ e a sutura claval. Apêndice desenvolvido, alcançando $\mathrm{M}_{3+4}$.

Espinulação das tíbias anteriores $1+4$ e dos fêmures posteriores $2+2+1$.

Pigóforo com um par de processos espiniformes subapicais e um par de apêndices basais, com o terço apical serreado Placas subgenitais triangulares; macrocerdas unisseriadas entremeadas de longos pêlos. Estilos falciformes. Edeago tubular curvo para cima; ápice levemente bífido. Gonóporo apical. Conetivo longo com braços divergentes.

Fêmea. Desconhecida

Comprimento total: $5,46 \mathrm{~mm}$.

Material examinado. Holótipo de Frequenamia particula DeLong do Panamá, Chiriqui: Fortuna (1050 m, $\left.8^{\circ} 44^{\prime} \mathrm{N} ; 82^{\circ} 15^{\prime} \mathrm{W}\right)$,
26.IX.1976, Henk Wolda leg. (Ohio State University, USA).

Comentário. DeLong (1982) quando descreveu e ilustrou a espécie considerou que o edeago apresentava um par de apêndices basais, saindo lateralmente. Ao analisarmos a genitália do holótipo afixada ao exemplar observamos que estava bastante danificada e, ainda, com restos de musculatura. Os apêndices citados na descrição original fazem parte do pigóforo e não do edeago. Os restos de musculatura e a proximidade dos apêndices com o edeago fizeram com que o autor interpretasse erroneamente a localização da estrutura.

Sinchonoa Linnavuori \& DeLong, 1978 difere de Frequenamia DeLong, 1947 por apresentar a região frontal levemente intumescida enquanto que em Frequenamia esta é voltada para cima; asas anteriores concolores enquanto que em Frequenamia estas apresentam inúmeras manchas e falsas veias marrons; o tubo anal esclerotinizado lateralmente e em Frequenamia esclerotinizado lateralmente e dorsalmente; edeago tubular e sem apêndices e em Frequenamia este apresenta pelo menos um par de apêndices.

\section{AGRADECIMENTO}

Agradecemos ao Dr. Peter W. Kovarik, Museum of Biological Diversity, Ohio State university, USA, pelo empréstimo do holótipo.

\section{REFERÊNCIA BIBLIOGRÁFICA}

DeLong, D.M. 1982. New Central and South American leafhoppers of the "Bahita" group (Homoptera: Cicadellidae: Deltocephalinae). Proceeding of the Entomological Society of Washington 84 (1): 184-190. 

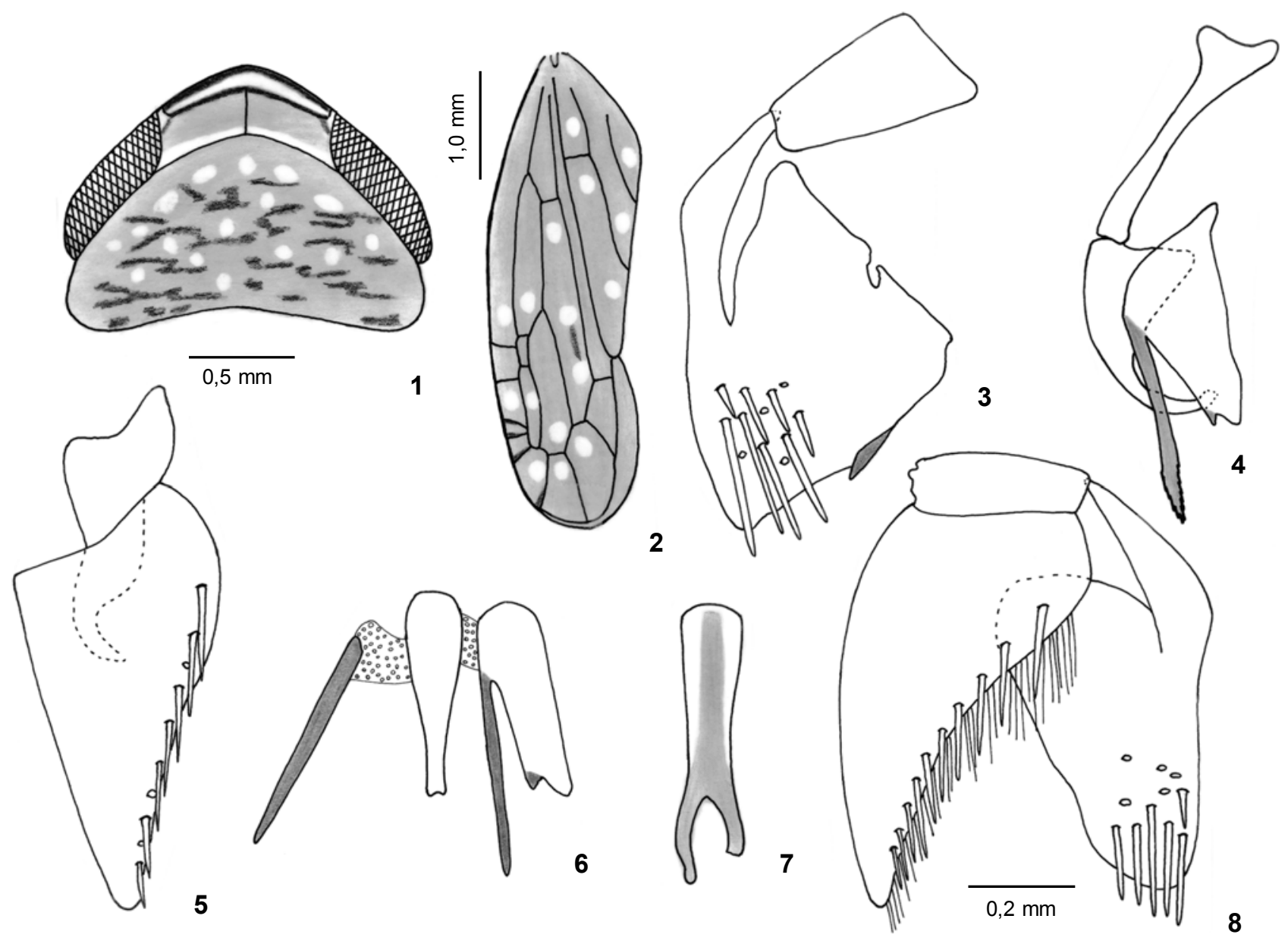

Figura 1-8. Frequenamia particula DeLong, 1982 (agora em Sinchonoa), holótipo macho: (1) cabeça e pronoto, dorsal; (2) asa anterior; (3) parte do pigóforo e valva genital, lateral; (4) conetivo, edeago e parte do pigóforo, lateral; (5) estilo e placa subgenital; (6) edeago e parte do pigóforo, ventral; (7) conetivo; (8) placa subgenital e parte do pigóforo e valva genital, lateral.

Recebido em 15.IV.2004; aceito em 03.VI.2004.

Revista Brasileira de Zoologia 21 (2): 343-344, junho 2004 